\title{
EDITORIAL
}

\section{In This Issue: Assessing and Acting on Complexity}

\author{
Kurt C. Stange, MD, PbD, Editor \\ Ann Fam Med 2012;10:98-99. doi:10.1370/afm.1386.
}

$\mathrm{T}$ his issue dives into the complexity of measuring multifaceted morbidity and of making policy in complex times. Diverse other articles look at lung cancer screening rates, medical-cultural factors fostering workplace harassment and abuse, and the evolving paradigm of the family physician.

\section{MEASURING MULTIMORBIDITY}

Three Methodology articles build on the theme of multimorbidity from the last issue of Annals. They are particularly important because often what is not measured is not valued. These articles perform the vital service of giving us tools to assess, value, and integrate peoples' complexity.

It is hard enough sometimes to measure the presence of a single illness; the common situation of people having more than one condition presents even more challenges. Huntley and colleagues conduct a systematic review that highlights the utility and shortcomings of existing measures of multimorbidity. ${ }^{1}$ In another systematic review, Fortin et al find huge differences in the rates of multimorbidity measured in the population and in primary care. ${ }^{2}$ Bayliss and colleagues examine two different approaches to gauging morbidity and find that both subjective and objective data are needed. ${ }^{3}$ Finally, an editorial from the US Department of Health and Human Services describes the organization's new strategic framework for a coordinated and comprehensive approach to caring for patients with multiple chronic conditions. As the editorial states, this is "an enormous health system challenge that demands our urgent attention. ${ }^{4}$ Together, these articles, as well as prior multimorbidity articles in Annals, ${ }^{5}$ are helping to build a basic science of multimorbidity as a target for investigation and intervention. This line of inquiry could have vitally important ramifications by improving the value of health care, helping to create sustainable health care systems, and reducing human suffering.

\section{PROMISING POLICIES TO STAY AHEAD OF SPEEDILY SHIFTING SOCIETAL SANDS}

Three Special Reports and a Reflection draw attention to policy initiatives and implications of the rapidly changing US health care environment.

An overview by the director of the Seamless Care Models Group at the Center for Medicare and Medicaid Innovation highlights the opportunities and accountabilities created by a bevy of new primary care programs. ${ }^{6}$ These new initiatives provide mechanisms to reform health care to be more effective and sustainable. They are worth paying attention to and participating in. They are an opportunity for leadership to make things better.

Another special article updates estimates of who will be able to afford health insurance in the future, in light of the Patient Protection and Affordable Care Act that reformed health care payment in the United States. ${ }^{7}$ Strikingly, they find that a family's health insurance costs will equal median household income by the year 2033

Phillips and Turner analyze the high yield of expanded Title VII program investment to revitalize the national primary care workforce that is essential if the US health care system's ineffectiveness and unsustainability is to be overcome. ${ }^{8}$

A Reflection by Saba wistfully revisits the heroic figure of the mythical lone physician and presents an alternative for the modern era. This essay thumps at the heart of our self-image as family physicians and opens a skylight to a more inclusive alternative. We feature this essay in the Annals Journal Club to encourage young readers to unearth a new path that is true to the timeless ideals but reinvented for a new time. ${ }^{9}$

\section{DIVERSE TOPICS}

Klabunde and colleagues find a surprisingly high rate of use of lung cancer screening tests by primary care physicians in response to different clinical vignettes. ${ }^{10}$ 
An in-depth study of family physicians in Canada uncovers elements of the workplace culture that appear to contribute to work related harassment and abuse. ${ }^{11}$ The authors identify the training period as a critical time to interrupt cultural cycles that perpetuate harassment and abuse.

A Methodology article shows how the video elicitation interview can be useful to investigate, understand, and improve clinician-patient interactions. ${ }^{12}$

Please join the discussion of these and other articles at http://www.AnnFamMed.org

\section{CHANGES IN THE ANNALS EDITORIAL ADVISORY BOARD}

The Annals' Editorial Advisory Board plays a crucial role in guiding the journal's direction. The editorial team would like to thank the following individuals who completed their Board terms in 2011. Their commitment and wisdom were particularly important in shaping the Annals during its early years: Jessie Gruman, $\mathrm{PhD}_{i}$ Eva Kahana, $\mathrm{PhD}_{i}$ Professor Bruce Sparks, Roger Strasser, $\mathrm{MD}_{i}$ Gregory Strayhorn, $\mathrm{MD}, \mathrm{PhD}_{i}$ and Paul Thomas, MB, ChB, DCH, MRCGP. I am personally grateful for all that these friends did to help move the Annals from an ambitious idea to an ongoing forum.

We're delighted to welcome these new members to the Board in 2012: Richard Antonelli, MD, MS, Jennifer DeVoe, MDi Susan Edgman-Levitan, PA, Professor Trisha Greenhalgh; Professor Jane Gunn; Michelle Kraft, MLS, AHIP; Robert Law, MDi M. Norman Oliver, MD, MA, Wilson D. Pace, MDi Robert L. Phillips, Jr, MD, MSPH ${ }_{i}$ Professor Steve Reid ${ }_{i}$ Marino Rivera; Jack Westfall, $\mathrm{MD}_{i}$ and Steven Woolf, MD, MPH. The editorial team looks forward to your wisdom, your challenges, and your efforts to make new connections.

\section{References}

1. Huntley AL, Johnson R, Purdy S, Valderas JM, Salisbury C. Measures of multimorbidity and morbidity burden for use in primary care and community settings: a systematic review and guide. Ann Fam Med. 2012;10(2):134-141.

2. Fortin M, Stewart M, Poitras M, Almirall J, Maddocks H. A systematic review of prevalence studies on multimorbidity: toward a more uniform methodology. Ann Fam Med. 2012;10(2):142-151.

3. Bayliss EA, Ellis JL, Shoup JA, Zeng C, McQuillan DB, Steiner JF. Association of patient-centered outcomes with patient-reported and ICD-9-based morbidity measures. Ann Fam Med. 2012;10(2):126-133.

4. Goodman RA, Parekh AK, Koh HK. Toward a more cogent approach to the challenges of multimorbidity. Ann Fam Med. 2012;10(2):100-101

5. Annals of Family Medicine. Multimorbidity [web page]. http://www .annfammed.org/cgi/collection/multimorbidity.

6. Baron RJ. New pathways for primary care: an update on primary care programs from the Innovation Center at CMS. Ann Fam Med. 2012;10(2):152-155.

7. Young RA, DeVoe JE. Who will have health insurance in the future? An updated projection. Ann Fam Med. 2012;10(2):156-162.

8. Phillips RL Jr, Turner BJ. The next phase of Title VII funding for training primary care physicians for America's health care needs. Ann Fam Med. 2012;10(2):163-168.

9. Saba GW, Villela TJ, Chen E, Hammer H, Bodenheimer T. The myth of the lone physician: toward a collaborative alternative. Ann Fam Med. 2012;10(2):169-173.

10. Klabunde CN, Marcus PM, Han PKJ, et al. Lung cancer screening practices of primary care physicians: results from a national survey. Ann Fam Med. 2012;10(2):102-110.

11. Miedema B, Maclntyre L, Tatemichi S, et al. How the medical culture contributes to coworker-perpetrated harassment and abuse of family physicians. Ann Fam Med. 2012;10(2):111-117.

12. Henry SG, Fetters MD. Video elicitation interviews: a qualitative research method for investigating physician-patient interactions. Ann Fam Med. 2012;10(2):118-125. 